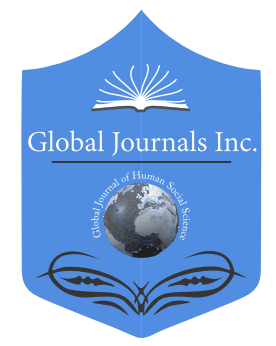

\title{
Exploring Strategic Opportunities for Better Learning. Student Concerns at a Private University
}

By Miguel Agustín Ortega Carrillo

De La Salle Bajío University

Abstract- This work documents the first actions that have been carried out to generate organizational strategies aimed at achieving a better learning experience among university students. As a result of the confinement conditions imposed by the pandemic since 2020, it is estimated that eventually a hybrid education system will be reached where remote and face-to-face formats are combined. Anticipating which are the best practices that can be developed in each modality, a study was carried out among several students of a Mexican Higher Education Institution where the concerns they have about their learning experience were explored. This is a mixed investigation, where, based on the results of a survey among a non-probabilistic population sample, a strategic analysis of organizational opportunities was carried out for its application in a specific university space. The discussion section offers some of the conclusions obtained, as well as concrete actions that are being evaluated in pilot tests with students from a private university.

Keywords: remote education, learning orientation, organizational strategies, organizational innovation.

GJHSS-G Classification: FOR Code: 930199p

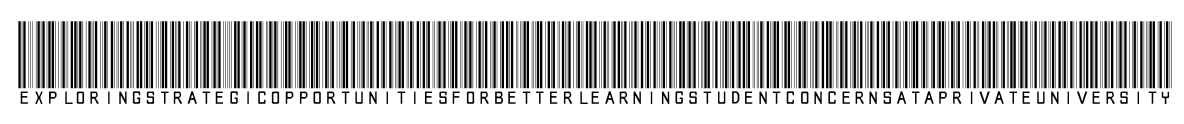

Strictly as per the compliance and regulations of:

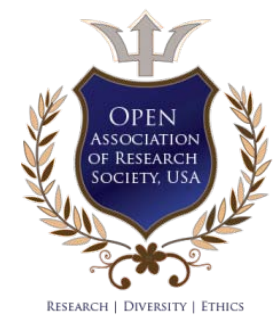

(c) 2021. Miguel Agustín Ortega Carrillo. This is a research/review paper, distributed under the terms of the Creative Commons Attribution-Noncommercial 3.0 Unported License http://creativecommons.org/licenses/by-nc/3.0/), permitting all non-commercial use, distribution, and reproduction in any medium, provided the original work is properly cited. 


\title{
Exploring Strategic Opportunities for Better Learning. Student Concerns at a Private University
}

\author{
Miguel Agustín Ortega Carrillo
}

\begin{abstract}
This work documents the first actions that have been carried out to generate organizational strategies aimed at achieving a better learning experience among university students. As a result of the confinement conditions imposed by the pandemic since 2020 , it is estimated that eventually a hybrid education system will be reached where remote and face-to-face formats are combined. Anticipating which are the best practices that can be developed in each modality, a study was carried out among several students of a Mexican Higher Education Institution where the concerns they have about their learning experience were explored. This is a mixed investigation, where, based on the results of a survey among a non-probabilistic population sample, a strategic analysis of organizational opportunities was carried out for its application in a specific university space. The discussion section offers some of the conclusions obtained, as well as concrete actions that are being evaluated in pilot tests with students from a private university.
\end{abstract}

Keywords: remote education, learning orientation, organizational strategies, organizational innovation.

\section{BACKGROUND}

- The pandemic caused by COVID-19, during 2020 and so far in 2021, caused education institutions to suddenly opt for an education modality based on ICTs. Since then, multiple studies have been carried out on the psychosocial risks that have originated since this change (Javier-Murillo \& Duk, 2020). A less explored aspect is how study habits have been modified and how, from the forced change of teaching methods, some of the benefits that ICTs potentially offer, that have not been fully exploited in institutions, can be incorporated in combination with the traditional methods. From the organizational point of view, there is an opportunity for the lessons obtained about the teaching process in these conditions to be applied when there is an eventual return, be it sudden or gradual, to the classroom (Cabrera, 2020).

At De La Salle Bajío University, in its Business School, a project has been started to capitalize on this opportunity. The assumptions used for its development are the following:

- Eventually, the educational experience will be a combination of the face-to-face format and the remote format

- Face-to-face teaching will be well received in the short term, but will require creative efforts to keep students' attention in the medium and long term.

Author: Full-time Research Professor of the Faculty of Business at De La Salle Bajío University. e-mail: mortega@delasalle.edu.mx
- Remote education is ideal for the teaching of specific content as long as it attends to the creation of content that takes better advantage of the facilities that ICTs allow.

\section{Theoretical Development}

The relevant aspects of each of the assumptions on which this research is based are detailed below.

a) The hybrid model

The truth is that the change from the face-toface model to the remote model was not something planned, but was a reaction to the circumstances imposed by the confinement. On some occasions improvisation and difficulties in adapting to the circumstances imposed by the use of ICTs for remote communication and the educational process predominated (García-Ruiz \& Pérez-Escoda, 2020). There has been a lot of talk from institutional settings of a return to a "normality" or the emergence of a "new normality". With regard to higher education, both notions can be somewhat sketchy, with the disadvantage that opportunities are no longer taken for students to experience more enriching learning (Cervantes-Holguín \& Gutiérrez-Sandoval, 2020).

An undesirable scenario is that everything experienced during confinement is left aside (Frank, 2020). That, as a reaction in the opposite direction to the compulsory use of technological devices for remote teaching, it is decided to use the classroom as the only learning space (Kim, 2020). At the other extreme, there is the idea that devices by themselves can be an instrument that allows self-taught learning in a personal and complete way. Although, in effect, technology has this potential, it is necessary to analyze which are the elements of face-to-face education that are irreplaceable.

This point is of special relevance for the continuity of Higher Education Institutions (Ken-Medkah, 2020). An obvious element that is offered as a service to enrolled students is the possibility of closer human contact and the possibility of interacting among peers, fostering emotional ties and collaboration that will be of great benefit in the professional development of graduates. The challenge is how to justify the role of teachers before the latent possibility for people of being able to learn in greater depth any subject with specific content through the use of the Internet and adequate 
access to sources of information. In any case, the strategic challenge that is presented in Higher Education Institutions has at least these two relevant aspects: how to best balance face-to-face and remote modalities as part of their education services and, second, which role will assume teachers to ensure their continuity in the teaching process, given the possibility that students could to learn with greater solvency various topics and specific content through technological means.

\section{b) Learning practices in the face-to-face modality \\ According to the latest study presented by the} World Economic Forum [WEF] on future prospects in the workplace, it is evident that work is increasingly immaterialized, that is, the resources through which it is executed are increasingly intangible. The development of advanced technologies point towards that trend. This requires greater specialization and rigorous technical knowledge in various fields. However, the same study indicates that the personal skills in the labor field necessary in this context are soft skills, such as the capacity for analytical thinking and innovation, solving complex problems, critical thinking and analysis, creativity, originality and initiative. These types of competences are often not explicitly indicated in the study plans. However, they are key in the student experience (WEF, 2020). The evolution that they make of their educational experience inseparably has an emotional and intuitive element, in addition to the rational element most evident during their training.

On the other hand, other key services that a University offers, in addition to education, are infrastructure, possibility of establishing fruitful connections and prestige. Although these can eventually be offered from platforms and digital media, we are still far from the point where they are as attractive as when they are experienced in person. Considering the above, the opportunity presented in the current context of gradual exit from confinement is to develop strategies thinking about the face-to-face space as an ideal setting for students to reinforce their soft skills and where attention is paid to how you are favoring learning effective content specific to each area and discipline.

\section{c) Learning practices in remote mode}

Before the pandemic, there were many successful cases of the use of technology for learning (Iglesias, González, Lalueza, \& Esteban, 2020). For example, the work of Sugata Mitra, about groups of children who were allowed to organize themselves to learn on their own about the computer, become familiar with a foreign language, and learn about scientific subjects, has been replicated with good results in various countries. This offers empirical evidence that it is possible to take advantage of the benefits that the Internet offers for a quality education. It is worth noting that, in one of its stages, this project also included external support assistance to reinforce children's learning. Although this support was not provided by experts, it was found that the application of socialization skills provided by other people outside the groups of students does have a positive effect on learning (Majluf, 2013).

One case in which the potential of technologies has been systematized to the extent that a learning methodology has already been institutionalized through the use of digital content in learning, is that of the Khan Academy. At first, it was a family effort to help a young teenager learn math through videos. This allows to acquire an own rhythm of learning for each student. The value of this effort is that the importance of creating own content for a new communication medium and taking advantage of the facilities of the same medium was understood. The result is that, regardless of the context in which a student finds himself, if he has the technological means to access these contents, he can learn subjects not only in mathematics but also in other subjects quite efficiently (Oppenheimer, 2015). Here, personal accompaniment is exercised by experts, who no longer direct their efforts to the creation of the contents in classrooms, but to respond in a solvent way to the doubts that arise among students when they are already motivated in learning the subjects (Sánchez Otero et al., 2019).

Thus, there is the possibility of creating impressive content prepared by multidisciplinary teams that integrate design, programming, narrative and specific knowledge of the topics that captivates and attracts the attention of students more effectively than can be done on average in a classroom. The possibilities offered by internet formats, such as videos, and social networks, is to combine elements of memory by association, alternate repetitions, effective recovery, and the use of multiple sensory stimuli in the topics (Roediger III et al., 2018). The challenge, from an organizational point of view, is how to generate this type of content and, at the same time, guarantee that students are attracted to them (Sánchez-Murgas, 2020).

\section{d) Conceptual model}

Based on the research assumptions, a project is being developed in which, based on the students' testimonies of what their learning experience has been, organizational strategies are developed to apply best practices in the educational process (Jaramillo-Morales et al., 2020). These strategies are intended to foresee both an impact on educational services and the identification of innovation opportunities. As part of this effort, the following project concept map shown in Figure 1 has been developed: 

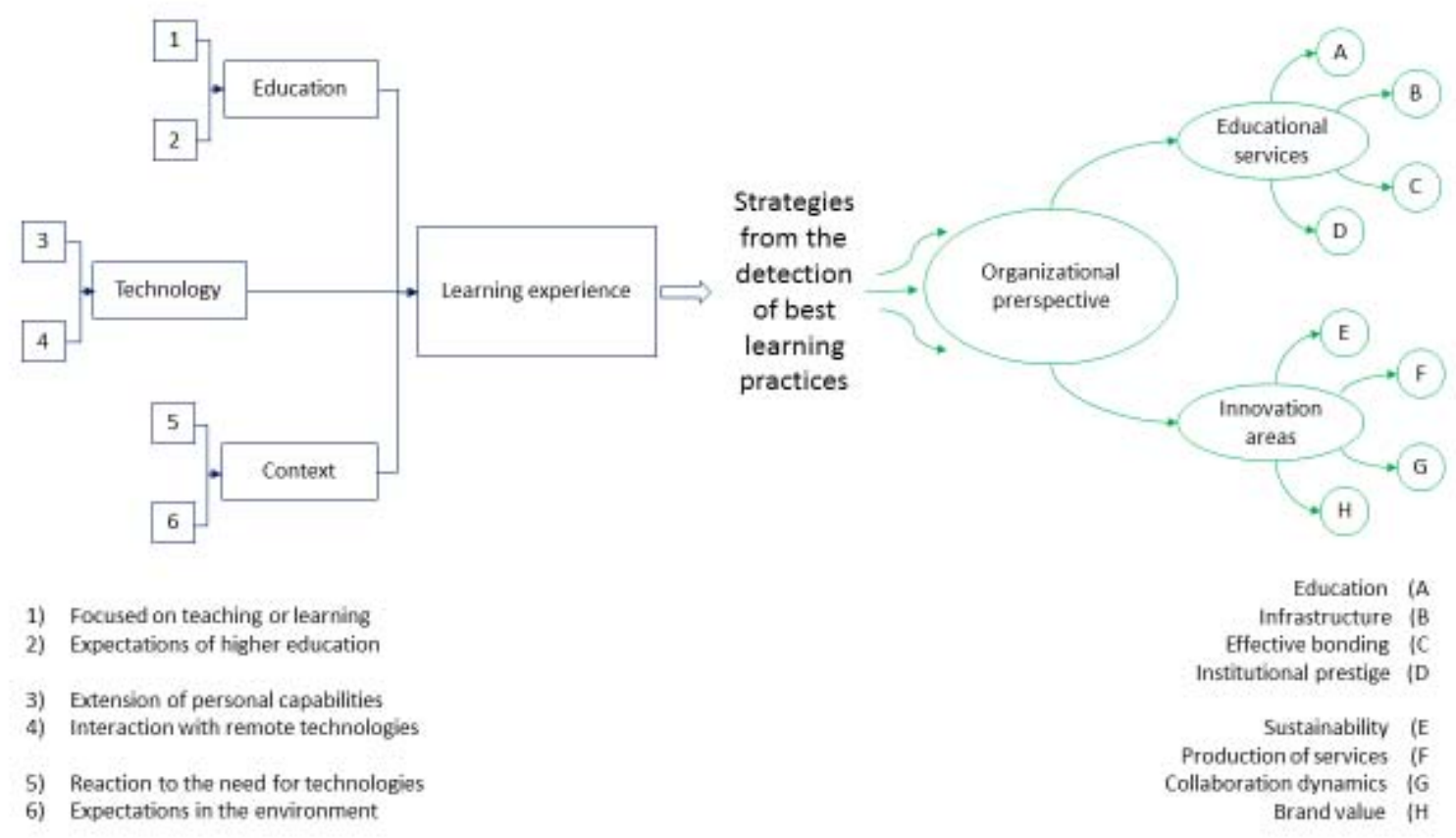

1) Focused on teaching or learning

2) Expectations of higher education

3) Extension of personal capabilities

4) Interaction with remote technologies

5) Reaction to the need for technologies

6) Expectations in the environment

Source: Ortega Carrillo \& Caldera González, 2021

Figure 1: Conceptual model of the research project.

This document presents results that explore the learning experience of a specific group of students in the field. It quantitatively shows the perceptions that were collected among De La Salle Bajío University students regarding the first point, that is, if they experience an education that focuses mainly on learning. It also inquires about how since what they have lived in confinement, they can assess the advantages that there are in educating themselves both in a face-toface mode and in a remote mode. Based on these results, work will be carried out at a later stage on a design of organizational strategies that take advantage of the knowledge acquired from these testimonies provided mainly by students interested in enriching their educational experience.

\section{Method}

The general objective of this work is to collect the concerns of students of the Faculty of Business of the De La Salle Bajío University, regarding their achievement of learning through the analysis of experiences in remote mode to generate organizational strategies to be applied in a hybrid format.

This research is of a mixed type. Its scope is descriptive, the approach is non-experimental and transversal. As part of its field design, a survey was developed and applied among a non-probabilistic population sample. Based on the obtained results, it was elaborated, semi-structured interviews were carried out among various students who expressed interest in the subject of study and whose contributions will be analyzed shortly. This document is part of a research project that explores the experience of students regarding their education, the use of technology and the social and economic context during 2020 and 2021. Based on the testimonies that have been collected among the students, discussion groups are being formed among some of them to delineate strategies that can be applied in an educational model that combines face-to-face and remoteness in education. Also, dynamics are being designed so that a pilot group of students propose the development of suitable content for learning in these new conditions.

Based on the experience of the students with respect to their education, a group of students was previously worked on in the elaboration of a conceptual map where the differences between the education that is more oriented to teaching were schematically identified (Edwards, 2018) and the one that is more oriented to learning (Robinson \& Aronica, 2016). The result is shown in figure 2 . 


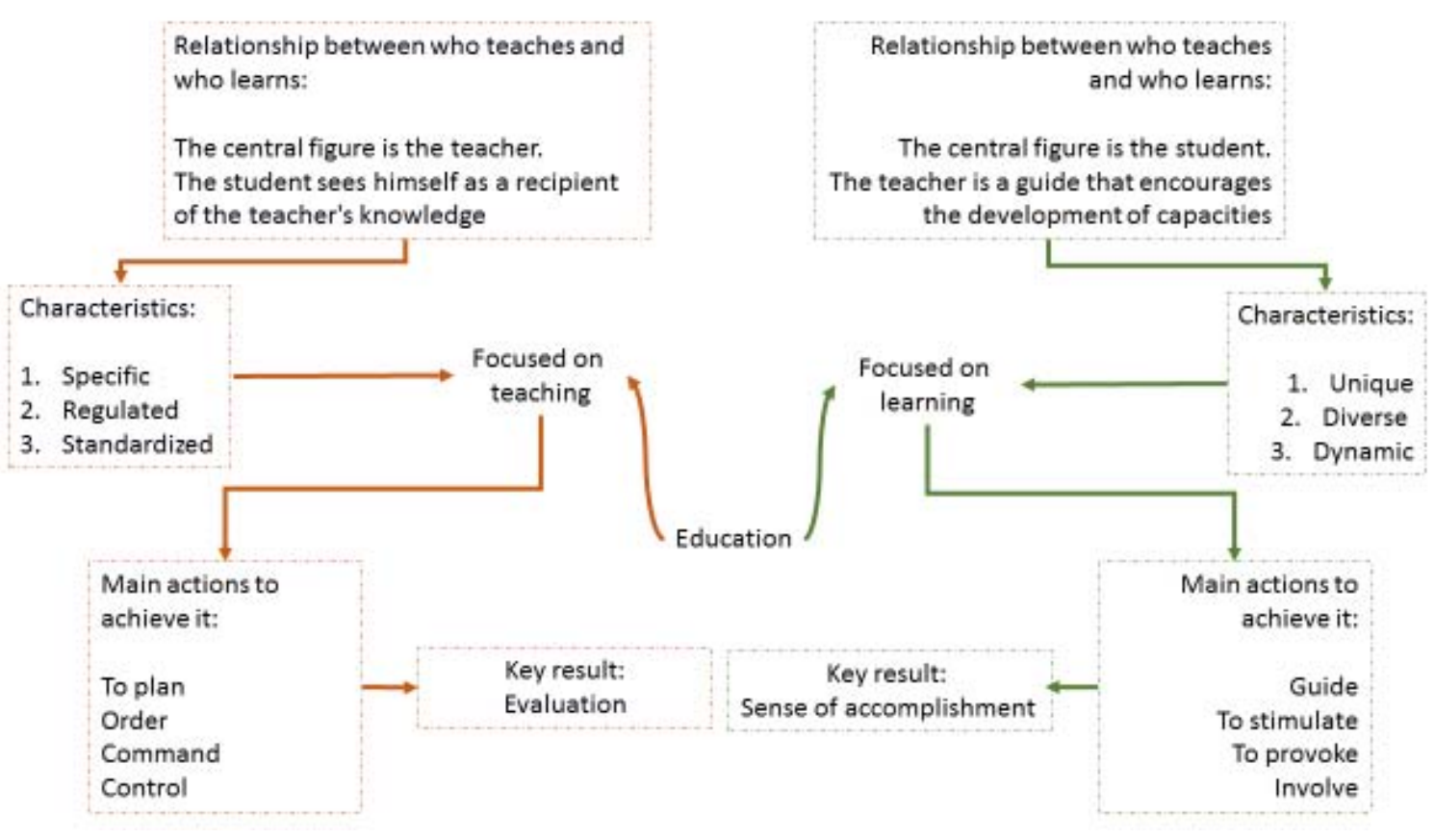

Source: Ortega Carrillo \& Caldera González, 2021

Figure 2: Differences between education focused on teaching or learning.

With this conceptual basis, a survey with 21 items that was published and applied from the QuestionPro platform. It was designed in collaboration with a team of six students from different educational institutions. Five of the items were used to identify demographic characteristics and the student situation of the respondents. Fifteen items were Likert-type, with scales that ranged from «very unsatisfied» to "very satisfied", where it was explored how close students perceive their situation to a learning-oriented education. The concepts that were emphasized were five: if the students felt well guided in their learning experiences, if they felt stimulated to continue learning, if they had been provoked in the sense of feeling invited to go further in the knowledge according to their own interests, if they felt really involved in their learning experience and, finally, if they recognized a sense of achievement in their learning (Robinson \& Aronica, 2016). To streamline student participation, only three items were devoted respectively to the key ideas "guide", "stimulate", "provoke" and "involve" and four about "sense of achievement". A second purpose of the survey was to raise awareness among the students who conducted it about their situation as protagonists of their own learning.

On the other hand, to explore the testimonies of the students regarding their perception of the differences between the modalities of face-to-face and remote education, two questions were asked in search of open answers: "What are the advantages that you experience in the remote modality? ", and «What are the advantages you experience in the face-to-face modality? ». A final question with a closed answer was aimed at detecting among the students who were interested in helping to create content on different topics for remote teaching and collaborating in interdisciplinary teams. The possible answers to this question were «Yes», «No», and «Maybe».

The survey was disseminated from the class spaces in the careers of the Faculty of Business of the De La Salle Bajío University where the students took research subjects - methodology and workshop and the voluntary partition of the undergraduate students was requested from both that Faculty, as well as others where careers related to other disciplines are taught. The response obtained was 96 students who completed the survey. The results obtained are described below.

\section{Results}

The survey was released among the community of undergraduate students at De La Salle Bajío University. There were 231 students who reviewed the instrument, of them 26 started it, but left it unfinished and only 70 answered their 23 questions complete, that is, $30.30 \%$. Given that a non-probabilistic sample was chosen, this percentage of participants only offers a notion of how many of those who knew about the research topic were interested in voluntarily providing their answers. In any case, in a parallel exercise that was carried out among students from other higher education institutions in Mexico, 91 complete responses were obtained from the 223 students who reviewed the instrument, including 50 who began to answer it, but left 
it unfinished. The number of complete responses represents $40.80 \%$ of those who had knowledge of the instrument. Therefore, although there is a reasonable similarity between the reaction of De La Salle students and other Mexican institutions regarding the low interest in participating in this study, there are reasonable elements to think that this disinterest is more accentuated at the De La Salle Bajío University.

Of the 96 participants who contributed complete answers, $64.29 \%$ are female and $35.71 \%$. The option « prefer not to answer» was also offered as option to respond about the sex of the student, but none of these participants chose it. Although there is a slightly higher number of women in the enrollment, these percentages offer a clue that it will be appropriate to analyze later regarding why women are more enthusiastic about reflecting on their educational experience. At the time of the survey, a percentage of $66.67 \%$ of the respondents was in the age range of 18 to 22 years, and the rest were older than 23 years. Participants study careers taught in the faculties of Business, Information Technology, Social Sciences and Humanities, Dentistry, Communication and Marketing, and Design. Those surveyed are currently studying from the second to the eighth semester of their career - the study plans contemplate 8 semesters in the case of all the careers described-. Regarding the concepts explored, it is shown below what is the perception of the students, especially in the aspects that offer the greatest opportunity for improvement.

\section{a) Properly guided learning}

To explore if the students feel that is their learning experience is well guided, three questions were asked: «Do you think that the study program of your career makes it clear to you what is the purpose of your profession? ", "Do you know and count with the necessary resources for your learning to be the best? " and «In the classes, in addition to covering the contents, did you feel accompanied to understand them? ». The first two questions generated mostly positive responses. However, given that the purpose of this diagnosis is to find areas of opportunity for the elaboration of strategies that make the student's experience more meaningful, we show here, in Figure 3, the result of the question in which the students were less satisfied.

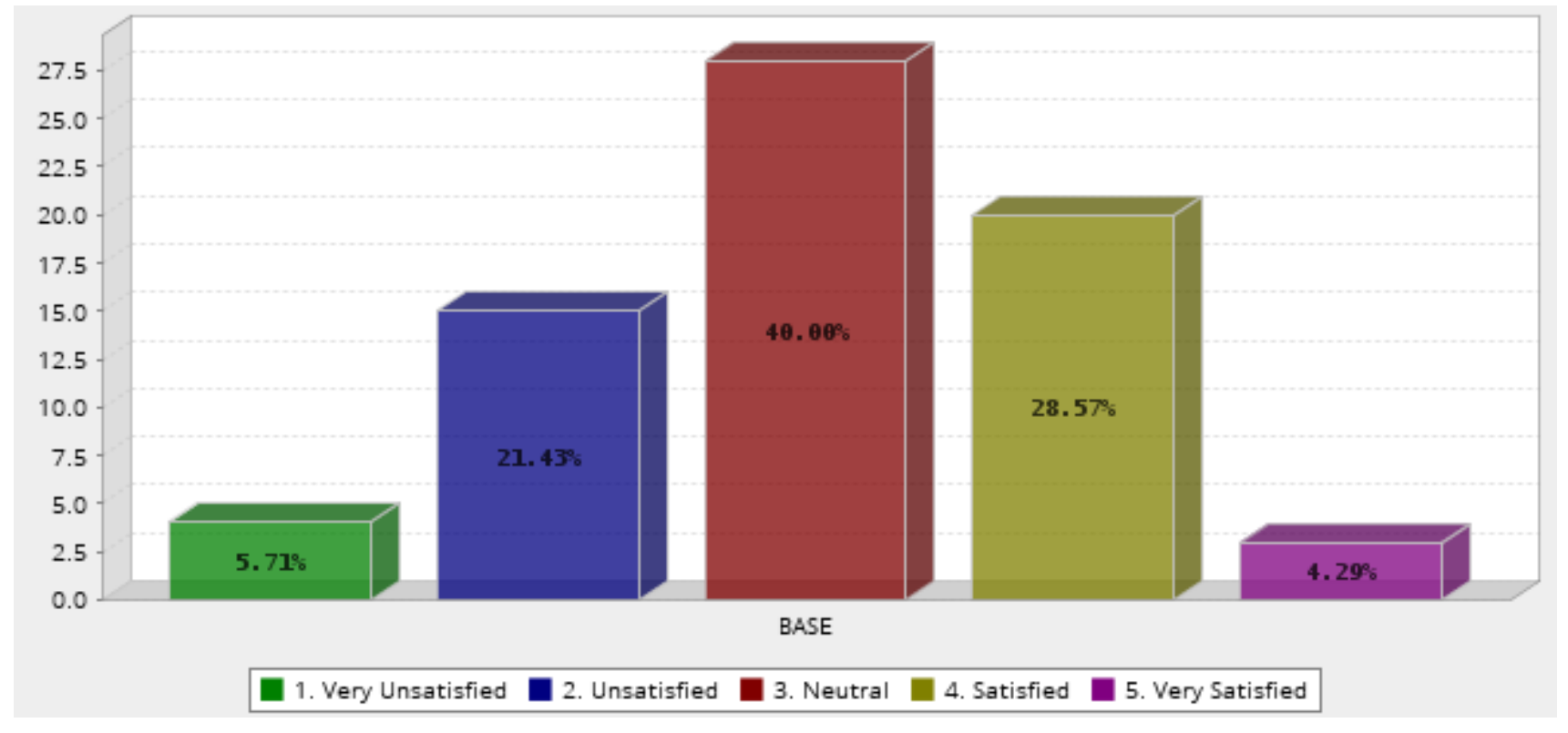

Source: Own elaboration using Question Pro tools

Figure 3: Answers to the question «ln the classes, in addition to covering the contents, did you feel accompanied to understand them?».

The main finding of this item is that approximately two out of every three students surveyed do not perceive personal accompaniment during their knowledge acquisition process.

\section{b) Stimulating learning processes}

To assess whether students experienced their educational processes as stimulating and motivating, three questions were asked: "Do you consider that you received the necessary motivation from your teachers?", «Do you feel encouraged to learn more on your own?» and «Do you consider school as a space for discovering new things in your life?» Although this last item's response obtained a very positive percentage among the average of the respondents - $87.14 \%$ of them expressed themselves between satisfied and very satisfied in this regard-, we again show, in Figure 4 in which of the items there was a response that indicates opportunities for intervention to make the student experience more stimulating. 


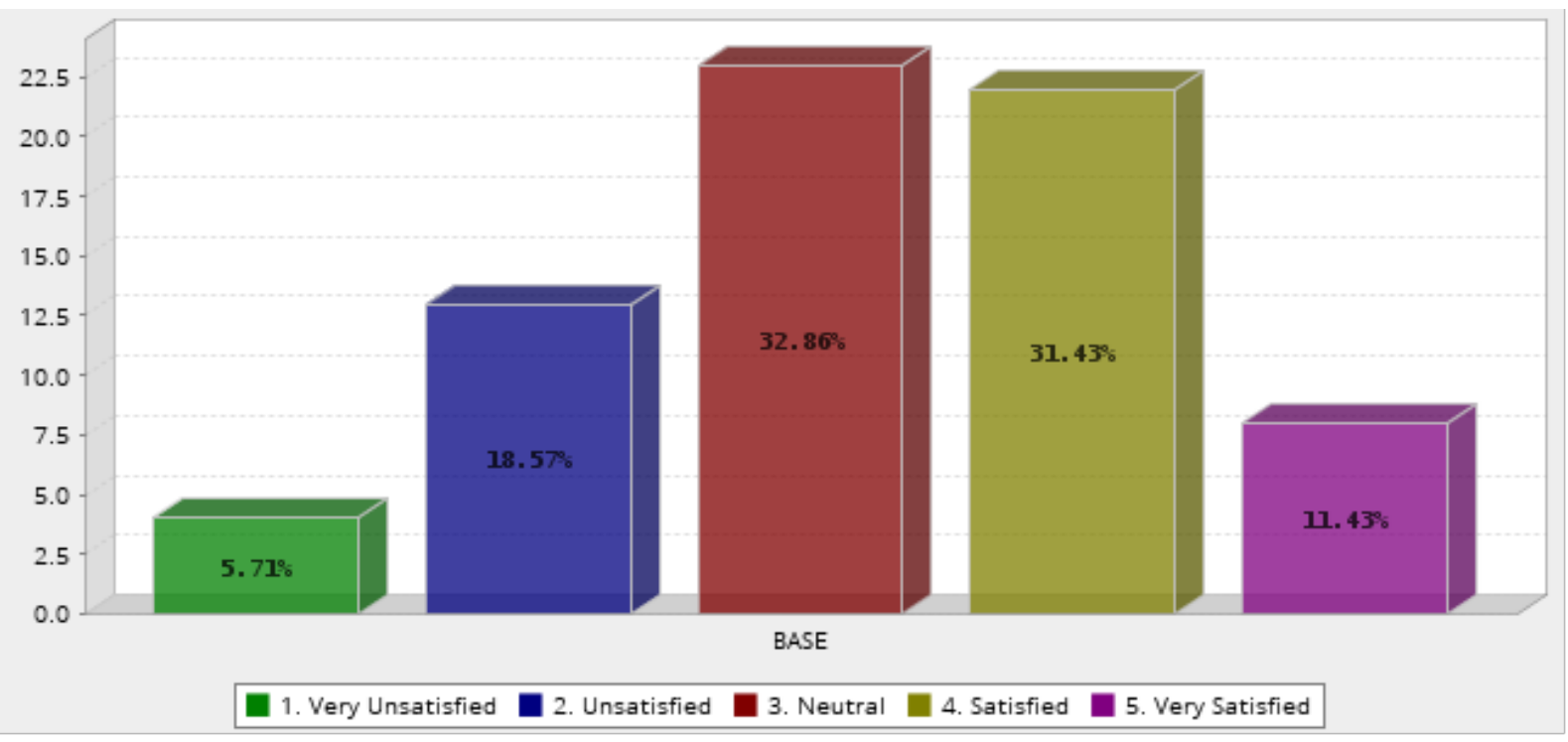

Source: Own elaboration using Question Pro tools

Figure 4: Answers to the question «Do you think you received the necessary motivation from your teachers?».

In this case, the perception among those surveyed is detected that teachers affect their motivation and that they do not necessarily do it for the better (Bozkurt \& Sharma, 2020). Although this point may be debatable, the fact is that $57.14 \%$ of them value it. This is a valuable input to consider in the subsequent organizational proposals that are being worked on as part of this project.

c) Feeling that the student is being provoked to go beyond the expected minimum

In order to find out if students feel provoked in a noble sense of the word, that is, if they are invited to go further with the knowledge they are acquiring, the following questions were asked: «Do you consider that your own initiative is important to develop yourself?», " Do you consider that your full potential is being used to make the classes more effective?» and «Have you found teachers who make you want to learn more on your own?» As with the previous dimension, there was a very positive response from $84.28 \%$ of those surveyed regarding having identified at least one teacher who encouraged them to continue acquiring knowledge. Even better was their perception regarding whether they consider their self-initiative relevant, as $95.71 \%$ of them weighed it. However, we present in Figure 5 the result of the question that represents the greatest concern for this study.

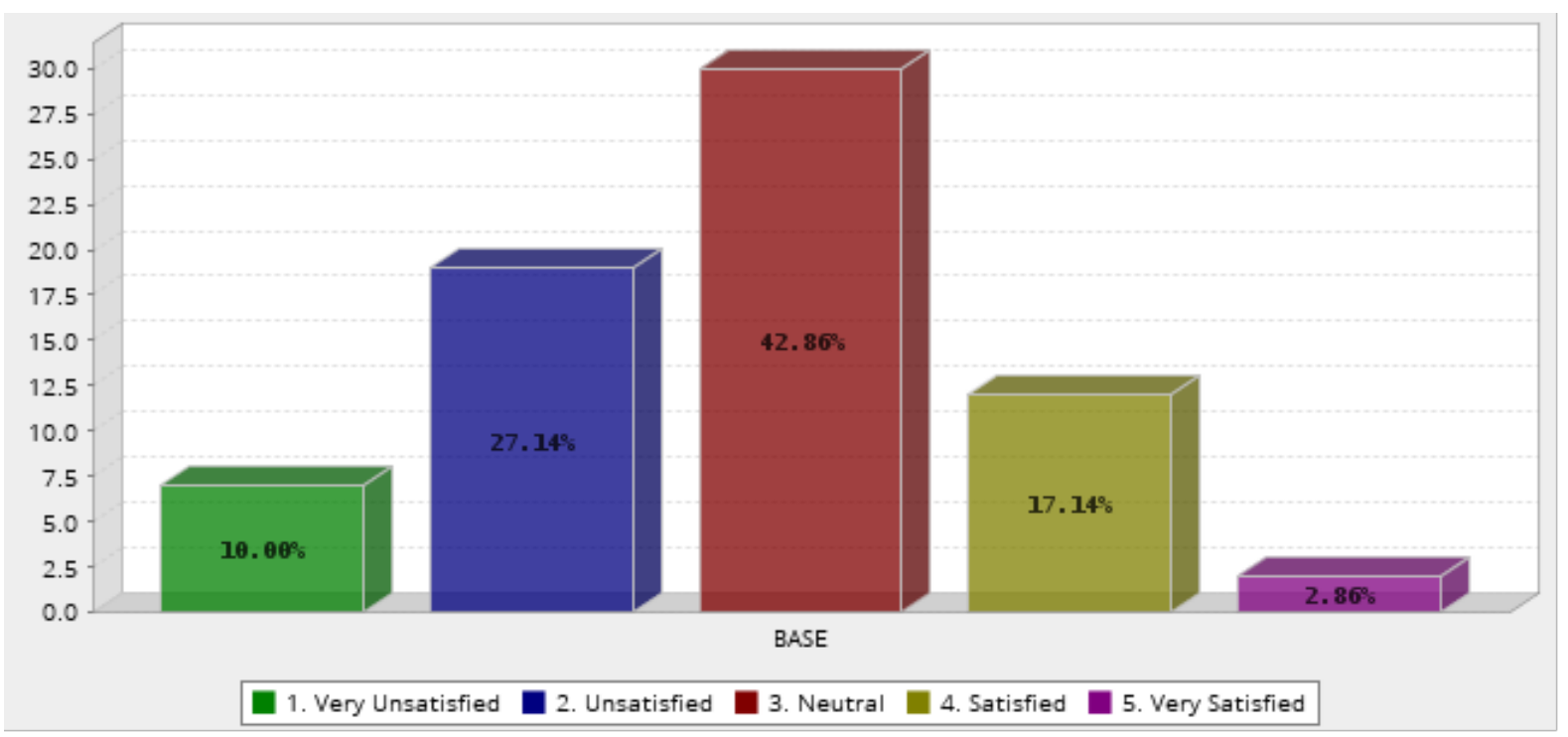

Source: Own elaboration using Question Pro tools

Figure 5: Answers to the question: «Do you consider that your full potential is being used to make classes more effective?» 
What is disturbing about this response is that it contradicts the stated perception of respondents that they value their own initiative and that they have identified teachers who push them to go beyond the minimum expected. It turns out that only one in five of those students who participated in this study clearly believes that they are taking advantage of their potential to make classes successful as a learning experience.

\section{d) Feeling of being really involved in your own education process}

To find out if students really feel involved in their learning process, three questions were asked: «Do you think that remote technology allows you to integrate well with your group?», «Have you participated with pleasure or do you feel motivated to collaborate? in extracurricular activities?» and «Do you think your experience at the University has made you a better person?». This last question was the one that yielded the best results in this case; $74.28 \%$ of the participants do consider that the university has transformed them for the better. It is still worrying, however, that one in four of them do not perceive it that way. Regarding the motivation to participate in activities other than those required, just more than half of them, $52.85 \%$, declare that it is part of their interests to carry out complementary activities.

This aspect is important because it speaks of an awareness, on the part of the students, of developing in a more comprehensive way according to their own personalities. Half of them who are not interested in doing more than standardized activities, shows that they probably do not find in the options offered by the institution, activities that are really related to them. Or worse still, that perhaps there is no conscious reflection on how to develop in different human dimensions and not only obey a defined professional profile. The result where there is more opportunity for strategic intervention is shown in Figure 6.

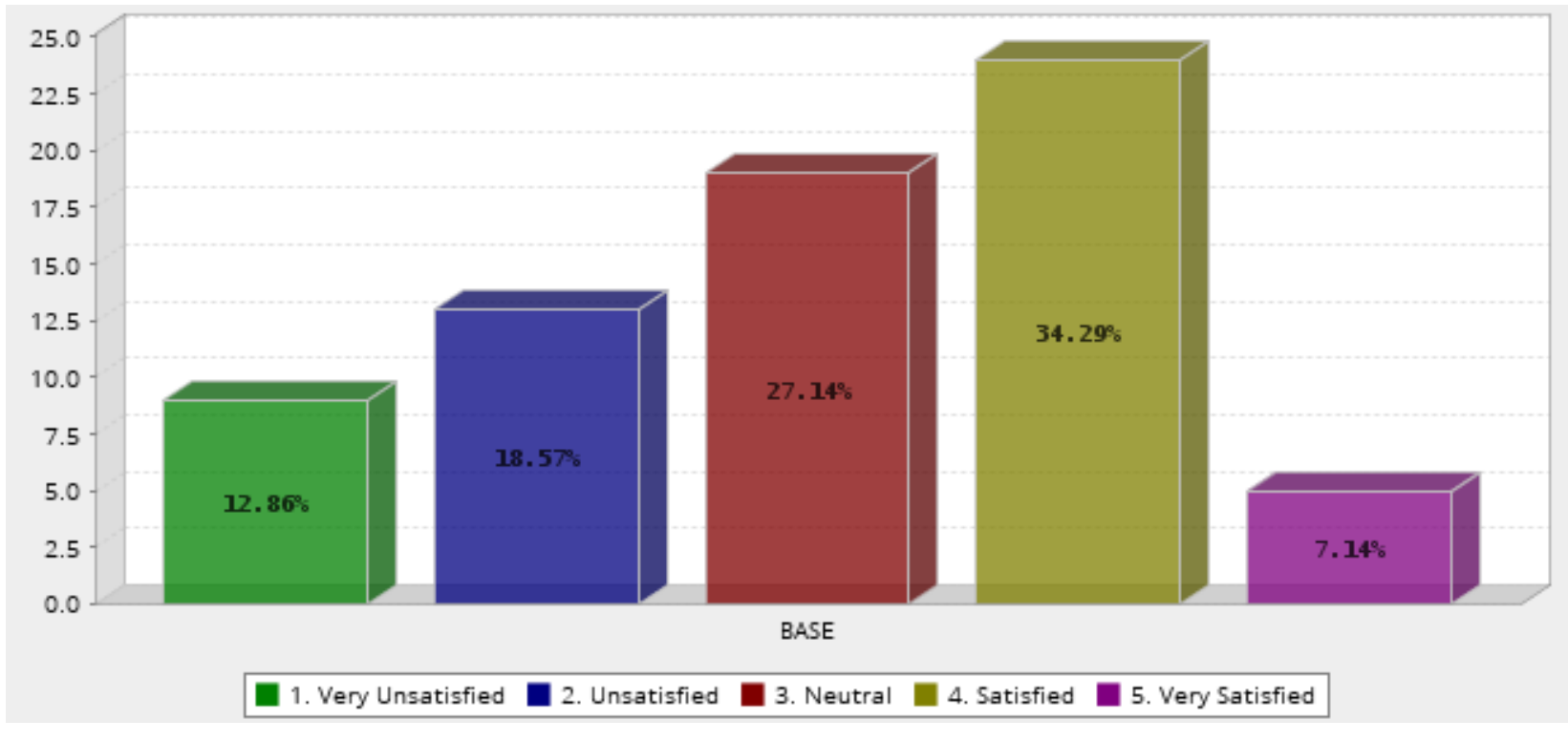

Source: Own elaboration using QuestionPro tools

Figure 6: Answers to the question: «Do you think that remote technology allows you to integrate well with your group?».

In this case, it is a question that is oriented, unlike the rest of those that were formulated, towards the specific experience in the remote mode. This exception was made given that the students have been immersed during this period in these conditions, they more frequently manifest in class the discomfort of not being able to have an effective coexistence with their classmates. Not only to establish affective and community relationships, but even to collaborate in school work (De-la-Hoz-Franco, et al., 2020). Although the result was not as serious as some of the spontaneous comments of the students would intuitively suggest, it was evidenced that at least $58.5 \%$ of them feel dissatisfied in this regard.

\section{e) Sense of achievement in learning}

To explore whether the students had obtained a sense of achievement with their learning, four questions were posed: "Do you consider the grades reflect what you have really learned?», "Do the conditions in which you study help you to perform well?", « Are you satisfied with what you have achieved and can you achieve with what you have learned in your career?» and "Has your university experience helped you to choose key aspects of your future?» The last two questions had mostly positive responses. The item that refers to whether the ideal conditions for better performance did not reach $50 \%$. However, the question that attracts the most attention and that is significant to consider in the 
elaboration of strategies, is the one illustrated in Figure 7.

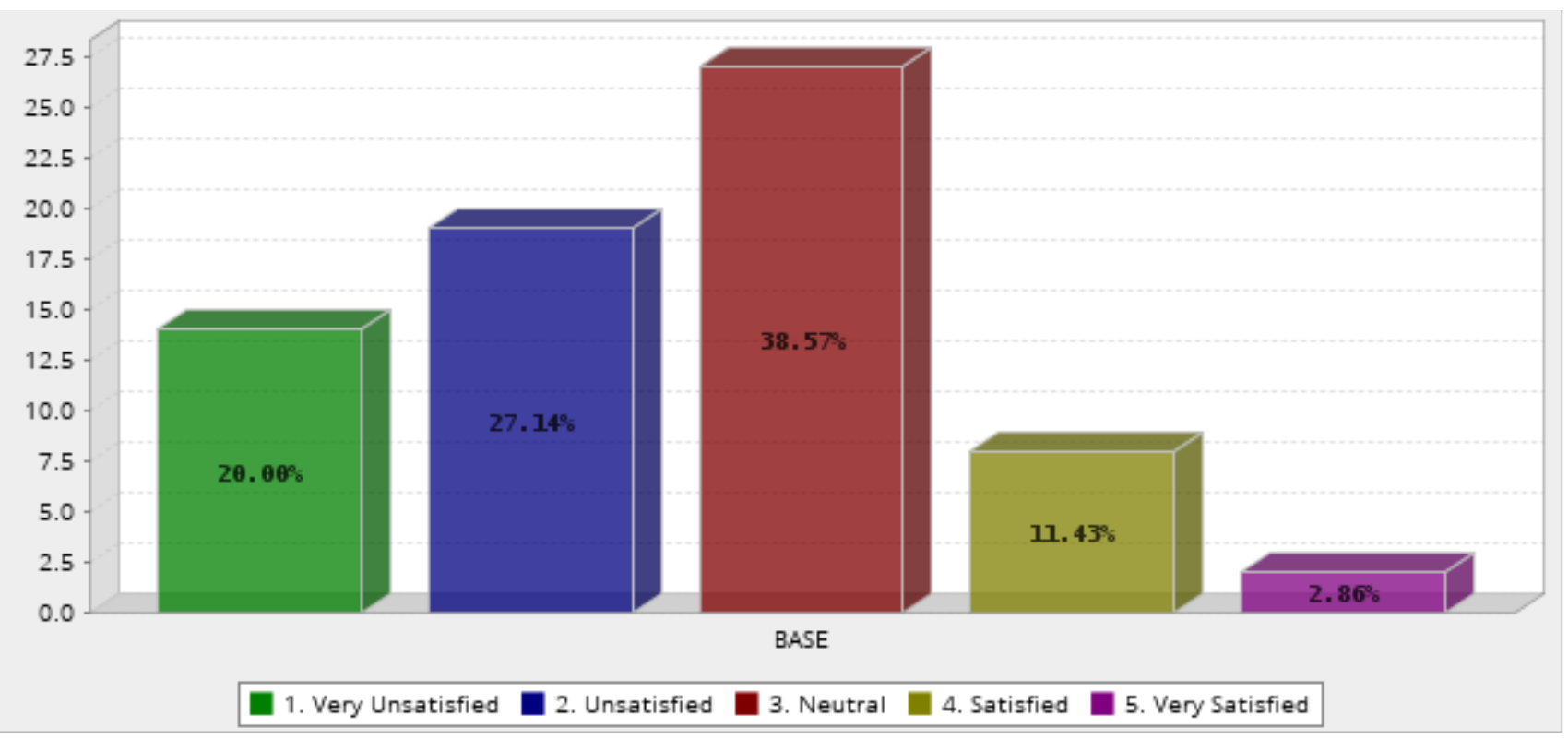

Source: Own elaboration using Question Pro tools

Figure 7: Answers to the question: «Do you consider the grades reflect what you have really learned?»

$85.71 \%$ of the participating students do not state categorically in agreement with this aspect. It is recognized, as a limitation of this study, that the applied instrument does not shed clues about the nuance of this result. That is, it cannot be concluded if in all cases in which the grade is considered not to reflect what has been learned, it is because the participants consider that the grade obtained was below the real learning or if there are cases in which it is considered that a high score does not imply significant learning. It is also understood that the high percentage of ambiguous answers, of $38.57 \%$, implies that for many of them there will be specific subjects in which they feel fairly evaluated and also some others in which they do not. What is relevant for the purposes of this research project is that - even when those who participated in this study already showed greater interest than the average in reflecting on their own experience - concern is detected on the part of the respondents because in addition to being evaluated, are accompanied in a learning process in a more comprehensive way.

\section{Discussion and Lines of Action Generated}

With the results obtained, we are working on the design of organizational strategies to provide the students of the Faculty of Business of the De La Salle University, a more enriching learning experience (Karpov, 2018). The reagents whose graph is shared in this document offer key elements to attend to in this process. According to the conceptual model illustrated in Figure 1, there are specific opportunities to take into account the issues in which students are dissatisfied to think about ways in which educational services are developed under the vision of significant improvement (Quiroz-Pacheco, 2017). This document shows five key aspects that have been detected and can be addressed. In terms of the strategic organizational thinking that is developed for this project, they can be expressed as follows:

1) Effective accompaniment in the student's learning process,

2) Attention to creating motivating atmospheres from the classroom,

3) Attentive listening to students to know their concerns regarding the development of their potential,

4) Search and design of dynamics that take advantage of the facilities of ICTs for sessions where there is greater integration between participants and

5) Offer added value to academic evaluation.

In the next stage of the development of this project, work is being done on analyzing how each of these aspects can be integrated or addressed through concrete actions that are reflected in the main four educational services offered by an educational institution of higher education. Those are: the education process, the infrastructure provided by the institution, the ability to effectively link students among peers and with actors from different social sectors, and institutional prestige. The vision of this organizational analysis also contemplates, as a next step, the development of 
proposals so that these services are not only improved, but are sustainable, have an organic and flexible process to propose themselves in specific spaces, generate collaborative learning and are meaningful and personalized to your beneficiaries.

Now, under the assumptions that guide this project, it is important to seek a balance between the face-to-face mode and the remote mode of education (Alves et al., 2020). The bet that arises from how progress has been made in research is to generate a conscious capacity to provide elements for students to strengthen and consider the importance of soft skills (Garrett, 2016). On the other hand, it is trusted that an effective way to compete in a digital environment where there will be an increasing number of powerful content for learning specific content available on the network, it is important to involve multidisciplinary teams of students for the creation of content from own learning (Dedós-Reyes, 2015). Both proposals are now explained in more detail.

Soft skills, as already mentioned, are considered essential for the workplace in the coming years. It is a trend that has been accentuating over time. In economic-administrative disciplines, where young people with skills to integrate teams with multiple spaces within organizations are trained, these competencies are key and despite them they are not always explicitly addressed within educational programs (Petersen et al., 2019). Well, the idea is to highlight its importance in the educational process of students. Given that this type of competences can be reinforced with practice as skills, the actions to be developed contemplate both the generation of spaces where they can be "tested" and their integration, even if it is partial in the interactions of the people who make up the institution with the students (Gutierrez-Moreno, 2020). Although all interaction of a group implies applying this type of competences with greater or lesser success, in this case what is emphasized is to call explicitly underlining its importance among those who make up the educational community.

On the other hand, the proposal to involve students in the creation of learning content has a strategic sense (Kristanto et al., 2017), especially from the perspective of their training in business careers. It is not proposed in the first instance that the contents that generate them compete with some of high quality that are elaborated by institutions that have a greater journey in this regard. But it is estimated that it is an excellent exercise for students to analyze a topic, synthesize it in a digital format, collaborate for its recording, editing, programming, narrative and sensory design. The benefits of learning projects have been explored in many studies. In this case, it is already part of a clear theme that will also bring benefits for other students who will be able to go to the collections that are generated with these contents (Esteban-Guitart et al., 2018).
Now, at this stage of the study, as mentioned, the feelings of the students regarding the advantages of the face-to-face and remote modes were also explored (González-Monfort, 2019), we decided to present the results of that part of the study in this discussion section because articulates very well with the strategic vision that inspires this project. Some of the following responses were detected among study participants when asked about the benefits they perceive in remote mode. The convenience of attending classes from anywhere was mainly pointed out. They talked about how comforting it is to avoid large transfers and save time: it was also indicated that it is pleasant to be close to loved ones, an issue that is highlighted when in the face-to-face format many of them had to come from foreign cities and remote places. Additionally, some considered that this format allowed them greater freedom and flexibility. These were the most recurrent responses. Note that there is not much emphasis on the thematic content and its quality (Pinker, 2017; Tarabini, 2020), however, there were among the 70 participating students, five of them who did point out positive aspects of the dynamics: more agile classes, without distractors and even recognition of teachers who used the format very well. In contrast, it is important to note that five other participants said that there was nothing positive in the remote mode. Two of them were even emphatic in their response that they did not find any positive aspect in the remote learning experience. Their short and blunt sentences with which they responded, respectively, were: "Absolutely nothing" and "NOTHING".

When they had the opportunity to express themselves about the advantages of the face-to-face modality, they said mainly, and quite extensively, how stimulating human coexistence is. Neither in this item were more than a few opinions expressed that underlined the quality of the teaching or of the course topics. On the other hand, some were specific in aspects related to coexistence, such as the opportunity to participate in sports activities and spaces to eat in a group. A response that has attracted attention to be considered in this research was one that pointed out that, in the face-to-face mode, teachers did not leave as many jobs as they did remotely. There are studies that explore in greater depth the psychosocial effects that the pandemic and distance education brought with it, but from the organizational point of view, we understand this response as a warning sign that in some cases has overreacted to the prejudice that students at home have more time, saturating them with homework.

The last item on which we leave a reflection in this work is whether the participants were willing to collaborate in the creation of the learning contents that have been previously mentioned. The expectation is that, since it is a non-probabilistic study, there would be a reasonable number of them who do express interest in this possibility, given that their willingness to answer the 
instrument already denotes a greater degree of interest in these tasks than an average student. The result was that, out of every four palpitations in the study, one declares that they are interested in creating content collaborating with other students, one declares that they are not and two say that maybe. These percentages, compared to a parallel study carried out among students from other institutions, is initially low. In fact, when students from other institutions were asked, $60 \%$ of them were enthusiastic about the possibility of collaborating in the content creation and only $30 \%$ rejected that possibility. From a strategic point of view, this gives us two readings that we find encouraging for the project. The first, that there are specific elements within De La Salle University that can be addressed so that the level of interest of these potential content creators is similar to what was detected in the other institutions. The other, closely related to the previous one, is that among the $50 \%$ who declared a "maybe" they represent a niche of students who can respond positively if they work well to provide them with better incentives.

\section{References Références Referencias}

1. Alves, T., Farenzena, N., Dragone-Silveira, A. A., \& de Rezende-Pinto, J. M. (2020). Implications of the COVID-19 pandemic on funding basic education. RAP: Revista Brasileira de Administração Pública, 54(4), 979-993. doi: http://dx.doi.org/10.1590/0034761220200279x

2. Bozkurt, A., \& Sharma, R. C. (2020). Emergency remote teaching in a time of global crisis due to Corona Virus pandemic. Asian Journal of Distance Education 15(1), i-vi. doi: https://doi.org/10. 5281/ zenodo.3778083

3. Cabrera, L. (2020). Efectos del coronavirus en el sistema de enseñanza: aumenta la desigualdad de oportunidades educativas en España. Revista de Sociología de la Educación-RASE, 13 (2) Especial, COVID-19, 114-139. doi: http://dx.doi.org/10. 7203/ RASE.13.2.17125.

4. Cervantes-Holguín, E., \& Gutiérrez-Sandoval, P. R. (2020). Resistir la Covid-19. Intersecciones en la Educación de. Revista Internacional de Educación para la Justicia Social, 9(3e). doi: https://doi.org/10. 15366/riejs2020.9.3.001

5. Dedós-Reyes, C. (2015). Integración de las redes sociales en el proceso de enseñanza y aprendizaje. Forum Empresarial 20(2), 31-50. doi: https://doi-org. e-revistas.ugto.mx/10.33801/fe.v20i2.3313

6. De-la-Hoz-Franco, E., Martínez-Palmera, O., Combita-Niño, H., \& Hernández-Palma 3, H. (2020). Las Tecnologías de la Información y la Comunicación y su Influencia en la Transformación de la Educación Superior en Colombia para Impulso de la Economía Global. Información
Tecnológica, 30(1), 255-263. doi: http://dx.doi.org/ 10.4067/S0718-07642019000100255

7. Edwards, R. (2018). An Elaboration of the Administrative Theory of the 14 Principles of Management by Henri Fayol. International Journal for Empirical Education and Research 1(1), 41-51.

8. Esteban-Guitart, M., Coll, C., \& Penuel, W. R. (2018). Learning across Settings and Time in the Digital Age. Digital Education Review, 33, 1-16. Obtenido de http://greav.ub.edu/der/

9. Frank, R. H. (2020). Under the influence: Putting peer pressure to work. Princeton: Princeton University Press.

10. García-Ruiz, R., \& Pérez-Escoda, A. (2020). Comunicación y Educación en un mundo digital y conectado. Presentación. Icono 14, 18(2), 1-15. doi:ri14.v18i2.1580|

11. Garrett, B. (2016). Metafísica. Artmed Editora.

12. González-Monfort, N. (2019). La Educación Patrimonial, Una Cuestión De Futuro. Reflexiones Sobre El Valor Del Patrimonio Para Seguir Avanzando Hacia Una Ciudadanía Crítica. Futuro Del Pasado: Revista Electrónica de Historia, 10, 123-144. doi: https://doi-org.e-revistas.ugto.mx/10. 14516/fdp.2019.010.001.004

13. Gutierrez-Moreno, A. (2020). Educación en tiempos de crisis sanitaria: Pandemia y educación. Praxis 16(1), 1-4. doi: http://dx.doi.org/10.21676/238978 56.3040

14. Iglesias, E., González, J., Lalueza, J., \& Esteban, M. (2020). Manifiesto en Tiempos de Pandemia: Por una Educación Crítica, Intergeneracional, Sostenible y Comunitaria. . Revista Internacional De Educación Para La Justicia Social, 9(3). doi: https://doi.org/10. 15366/riejs2020.9.3.010

15. Jaramillo-Morales, C. O., Conde-Pinzón, G. E., \& Londoño-Villamil, G. (2020). Modelo de diseño didáctico para la construcción de cursos virtuales: una propuesta en la modalidad de educación a distancia de la Universidad de la Amazonia. Revista Academia, 13(1), 23-36. doi: https://doi.org/10. 18359/ravi.2812

16. Javier-Murillo, F., \& Duk, C. (2020). El Covid-19 y las Brechas Educativas. Revista Latinoamericana de Educación Inclusiva, 14(1), 11-13. doi: http://dx.doi. org/10.4067/S0718-73782020000100011

17. Karpov, A. O. (2018). Designing the university's creative environment: Structural-functional analysis. En Science and Information Conference (págs. 319332). Cham: Springer.

18. Ken-Medkah, K. O. (2020). Enseñanaza en línea durante ña crisis del Covid-19 en la educación universitaria camerunesa: logros y desafíos. Ehquidad. International Welfare Policies and Social Work Journal, 14, 57-74. doi:10.15257/ehquidad. 2020.0012 
19. Kim, J. (2020). Learning and Teaching Online During Covid-19: Experiences of Student Teachers in an Early Childhood Education Practicu. International Journal of Early Childhood 52, 145-158. doi: https://doi.org/10.1007/s13158-020-00272-6

20. Kristanto, A., Mustaji, \& Marion, A. (2017). The Development of Instructional Materials E-Learning Based on Blended Learning. International Education Studies, 10(7), 10-17. doi: https://doi.org/10.5539/ ies.v10n7p10

21. Majluf, P. (5 de 5 de 2013). Afinidades eclécticas. Cómo el Internet podría salvar la educación en México: http://pablomajluf.mx/como-el-internetpodria-salvar-la-educacion-en-mexico/

22. Oppenheimer, A. (2015). iCrear o morir! La esperanza de Amércia Latina y las cinco claves de la innovación. Penguin Random House.

23. Ortega Carrillo, M. A., \& Caldera González, D. d. (2021). Organizational strategies for remote learning. Exploratory study during the pandemic at a private university. Technium Social Sciences Journal, 17. https://techniumscience.com/index. php/socialsciences/article/view/2700

24. Petersen, E., Fiske, A. P., \& Schubert, T. W. (2019). The Role of Social Relational Emotions for HumanNature Connectedness. Front Psychol, 10. doi:10. 3389/fpsyg.2019.02759

25. Pinker, S. (2017). La tabla rasa. La negación de la naturaleza humana. Barcelona: Espasa Libros, S.L.U.

26. Quiroz-Pacheco, Y. R. (2017). La educación y las nuevas tecnologías de la información y comunicación: la alfabetización digital. Cultura, 91, 195-220. doi: https://doi.org/10.24265/cultura. 2017. v31.11

27. Robinson, K., \& Aronica, L. (2016). Escuelas creativas. La revolución que está transformando la educación. Mexico: Penguin Random House.

28. Roediger III, H. L., \& McDaniel, P. C. (2018). Apréndetelo: La ciencia del aprendizaje exitoso. Paidós.

29. Sánchez-Murgas, O. (2020). Docencia en medio de la pandemia, un análisis en ciencias de la salud. Crea Ciencia Vol. 12 N. ${ }^{\circ}$ 2, 6-8. doi: https://doiorg.e-revistas.ugto.mx/10.5377/creaciencia.v12i2. 10164

30. Sánchez-Otero, M., García-Guiliany, J., SteffensSanabria, E., \& Hernández-Palma, H. (2019). Estrategias Pedagógicas en Procesos de Enseñanza y Aprendizaje en la Educación Superior incluyendo Tecnologías de la Información y las Comunicaciones. Información Tecnológica 30(3), 277-286. doi: http://dx.doi.org/10.4067/S0718-0764 2019000300277

31. Tarabini, A. (2020). ¿Para qué sirve la escuela? Reflexiones sociológicas en tiempos de pandemia global. Revista de Sociología de la Educación-RASE,
13 (2) Especial, COVID-19, 145-155. doi: http://dx. doi.org/10.7203/RASE.13.2.17135

32. WEF. (2020). The Future of Jobs Report 2020. World Economic Forum. Ginebra. Obtenido de http:// www3.weforum.org/docs/WEF_Future_of_Jobs_ 2020.pdf 